\title{
Knowledge, Attitude and Preparedness Regarding Ebola Virus Diseases among Health Care Workers in Pretoria: Private Hospital as a Case Study
}

\author{
OE Idowu and D Chetty*
}

Department of Health Care Sciences, Sefako Makgatho Health Sciences University, South Africa

*Corresponding author: D Chetty, Department of Health Care Sciences, Sefako Makgatho Health Sciences University, South Africa

\begin{abstract}
Background: In 2014 and 2015, large numbers of people, including health care workers ( $\mathrm{HCW}$ ) were infected and have died as a result of Ebola outbreak spread in West Africa. Presently, the diseases are still of a great concern for WHO because of its spreading in Republic of Congo, although it has decreased with the strike of COVID-19 pandemic.

Purpose: This study determined the knowledge and mindset of HCW about the disease (EDV) in private hospital in Pretoria, South Africa.

Methods: A quantitative, cross sectional survey was conducted in private hospitals. A self-administered questionnaire was used to collect information from 150 participants and was analyzed using descriptive summary statistics. The goal population included all the classes of the nursing staff in the hospital.

Results and discussion: The lack of relevant capabilities to treat Ebola in South Africa is the predominant situation to all respondents $(53 \%)$ followed with the aid of contracting the diseases (50\%). Seventy-nine percentages (79\%) indicated that the Ebola diseases can unfold in a private hospital, however, the readiness to care for patients with the diseases is a subject to $32 \%$ of the respondents. Sixty-eight percentages $(68 \%)$ of the respondents were confident that private hospitals could care for patients with the Ebola virus. Feelings of anxiety $(36 \%)$ and fear $(35 \%)$ used to be felt when providing services to patients with the Ebola disease.

Conclusion: There is no adequate, knowledge, mind-set and preparedness of the HCW in private hospital in Pretoria, South Africa towards Ebola Virus Diseases.
\end{abstract}

\section{Keywords}

Transmission, Clinical, Prevention, Confirm diagnosis, Symptoms

\section{Introduction}

In 2014 and 2015, large numbers of people, including health care workers ( $\mathrm{HCW}$ ) were infected and died as a result of Ebola virus disease, especially in West and Central Africa [1]. The Ebola virus disease (EVD) is an acute febrile disease caused by the Ebola virus. This virus is a member of the family of Filoviridae. EVD has a high mortality rate $(52 \%)$ in humans and non-human primates, from its initial recognition in the Democratic Republic of Congo in 1976 [2]. This disease was first identified in Nzara, South Sudan and in the Democratic Republic of Congo. In the Democratic Republic of Congo, the disease spread from a village near the Ebola and therefore received the name "Ebola" [3]. The most recent outbreak, which affected Guinea, Liberia, Sierra Leone and Nigeria in West Africa, was the worst in EVD history, with 2127 reported cases, and 1145 deaths [4]. The occurrence of EVD in the rain forests of Central Africa was also identified [5].

A multidisciplinary approach is applied in the treatment of Ebola, whereby the infected individuals are cared for at designated treatment centers and managed by trained clinicians [6]. All the Health Care Workers (HCW) who cares for infected or potentially infected patients should practice and adhere to strict infection control measures, including the use of personal protective equipment (PPE) [7]. The 2014 West African epidemic may have spread rapidly and widely due to the movement of infected individuals throughout the

Citation: Idowu O, Chetty D (2021) Knowledge, Attitude and Preparedness Regarding Ebola Virus Diseases among Health Care Workers in Pretoria: Private Hospital as a Case Study. Int Arch Nurs Health Care 7:160. doi.org/10.23937/2469-5823/1510160

Accepted: June 16, 2021: Published: June 18, 2021

Copyright: (C) 2021 Idowu O, et al. This is an open-access article distributed under the terms of the Creative Commons Attribution License, which permits unrestricted use, distribution, and reproduction in any medium, provided the original author and source are credited. 
region. The lack of adequate $\mathrm{PPE}$, as well as the illpreparedness of available HCWs, also increases the spread of this disease [4].

In South Africa, Hospital Acquired Infections (HAI) (Nosocomial) such as Crimean-Congo Haemorrhagic fever (CCHF) occurred in South African hospitals [8]. Recommendations were made by the Minister of Health $(\mathrm{MoH})$ to the health institutions, to develop policies to reduce the spread of the infection, which included the health care workers maintaining high standards of infection control measures and at all times as a means of preventing occupational exposure, and all the health care facilities should introduce measures and plans to manage the Viral Hemorrhagic Fever (VHF) [9].

The South African health care system needs to be

Table 1: Study population: List of the number of nursing staff working in the private hospital.

\begin{tabular}{|l|l|}
\hline Nursing staff & Number \\
\hline Professional Nurse & 100 \\
\hline Enrolled & 57 \\
\hline Auxiliary Nurse & 37 \\
\hline Student Nurse & 22 \\
\hline Care workers & 10 \\
\hline Total & 226 \\
\hline
\end{tabular}

strengthened regarding its preparedness to reduce the cases of nosocomial transmission of Ebola. All the HCWs need to access information on the warning signs about Ebola-related diseases. Hence, this study is aimed at determining the knowledge, attitude and preparedness of HCW against EVD in private hospital in South Africa.

\section{Materials and Methods}

\section{Study area}

The study was conducted in a private hospital in Central Pretoria. The Tshwane District is situated at the central of Pretoria, which is within the business center, close to government buildings, the union building railway, and bus and taxi stations, surrounded by residential houses, high rising flats, schools, and commercial properties. During morning and evening peak hours there is dense traffic, which is characteristic of any central business district. Others can walk to the hospital as it is situated close the main roads, and the off ramps to the highways to the South towards Pretoria North and in the South towards Pretoria East. The hospital offers 24-hour general and specialized health services for adults and children. The hospital receives referrals from family practitioners, by patients themselves, specialists, and public hospitals, with most of the patients being immigrants from Sub-Saharan Africa.

Table 2: Demographical information of the respondents.

\begin{tabular}{|c|c|c|c|}
\hline Category & Variables & Freq. & Percent \\
\hline \multirow[t]{2}{*}{ Gender } & $\begin{array}{l}\text { Female } \\
\text { Male }\end{array}$ & $\begin{array}{l}124 \\
9\end{array}$ & $\begin{array}{l}93 \% \\
7 \%\end{array}$ \\
\hline & Total & 133 & $100 \%$ \\
\hline \multirow[t]{2}{*}{ Age (years) } & $\begin{array}{l}20-30 \\
31-40 \\
41-50 \\
51-60\end{array}$ & $\begin{array}{l}30 \\
49 \\
34 \\
20\end{array}$ & $\begin{array}{l}23 \% \\
37 \% \\
26 \% \\
15 \%\end{array}$ \\
\hline & Total & 133 & $100 \%$ \\
\hline \multirow[t]{2}{*}{ Professional category } & $\begin{array}{l}\text { Registered nurse } \\
\text { Enrolled nurse } \\
\text { Enrolled nurse auxiliary } \\
\text { Student nurse } \\
\text { Care worker }\end{array}$ & $\begin{array}{l}52 \\
33 \\
34 \\
7 \\
7\end{array}$ & $\begin{array}{l}39 \% \\
25 \% \\
26 \% \\
5 \% \\
5 \%\end{array}$ \\
\hline & Total & 133 & $100 \%$ \\
\hline \multirow[t]{2}{*}{ Race } & $\begin{array}{l}\text { White } \\
\text { Indian } \\
\text { African } \\
\text { Coloured }\end{array}$ & $\begin{array}{l}12 \\
1 \\
117 \\
2\end{array}$ & $\begin{array}{l}9 \% \\
1 \% \\
88 \% \\
2 \%\end{array}$ \\
\hline & Total & 133 & $100 \%$ \\
\hline \multirow[t]{2}{*}{ Level of education } & $\begin{array}{l}\text { Matric } \\
\text { Tertiary } \\
\text { Other not specified } \\
\text { Other: care worker }\end{array}$ & $\begin{array}{l}30 \\
97 \\
5 \\
1\end{array}$ & $\begin{array}{l}22.5 \% \\
72.9 \% \\
3.6 \% \\
1 \%\end{array}$ \\
\hline & Total & 133 & $100 \%$ \\
\hline
\end{tabular}




\section{Study design}

In this study, the target population consisted of 226 healthcare workers, mainly professional nurses, enrolled nurses, auxiliary nursing assistants, student nurses and care workers. The table below shows the list of different health care workers (Table 1).

The private hospital selected for this study was Med Clinic Hospital Pretoria, being one of the largest private hospital which most received cases of Nosocomial. The study was conducted in January to December 2015. Data were collected using questionnaire administered (Supplementary file) by the hand to different wards where the staffs are working. The questionnaire was written in English with four different sections. The first section solicited for socio-demographic profile of the participant. The second sections asked the participant about their knowledge about Ebola Virus Disease, while third and fourth section asked the participant about their knowledge about control of Ebola Virus Disease and their attitude towards the control of Ebola Virus Disease (Table 2).

\section{Statistical analysis}

SPSS version 20.0 (IBM, Armonk, NY) was used for statistical analyses. Significance was assessed using the $c 2$ test. A P value $<0.05$ was considered to indicate statistical significance.

\section{Results}

Figure 1 showed the questions and the responses from the participant about their knowledge of on Ebola Virus Diseases.

The results shown in Figure $1 \mathrm{~A}$ show that $98 \%$ ( $\mathrm{n}$ $=129$ ) have heard about the Ebola Disease compared to $2 \%(n=3)$ who have not. Furthermore, $26 \%(n=33)$ of the respondents have received training, compared to $74 \%$ ( $n=94$ ) who did not receive any training on the Ebola Disease. Among the 33 respondents (Figure 1B) who indicated that they had received training on the Ebola Disease, the majority of the respondents indicated that 20 out of $33(63 \%)$ received this through in-service training, while 9 out of $33(28 \%)$ were through training courses, and 3 of $33(9 \%)$ were received through workshops. Other sources of information were received through colleagues, as indicated by seven respondents; while others indicated they heard this from a psychologist, an infection prevention and control (IPC) specialist, the community, an infection control system, a unit manager/clinical risk manager, a social
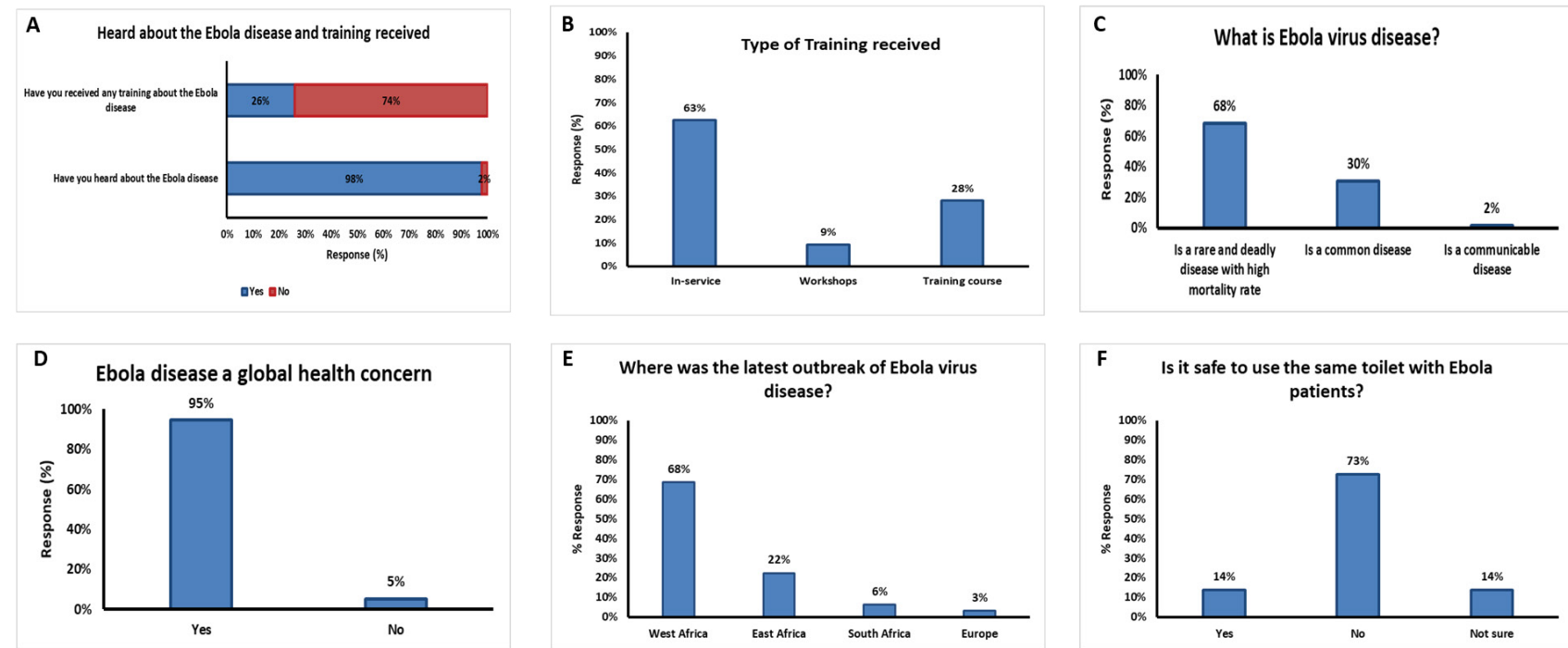

$\mathbf{F}$

Is it safe to use the same toilet with Ebola
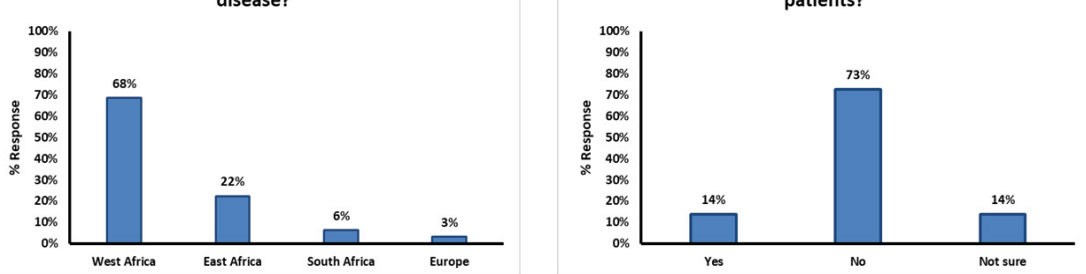

G What is the incubating period of the Ebola
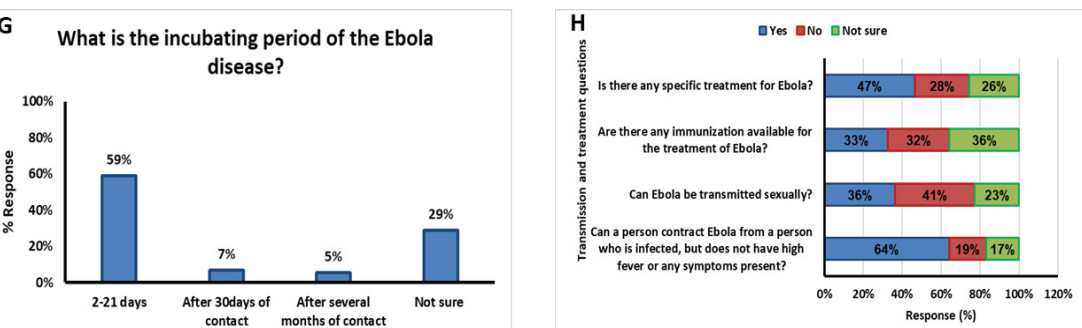

I What are the signs and symptoms of the

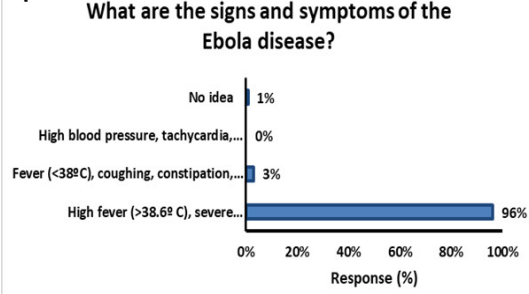

Figure 1: Questions and responses from the participants about their knowledge of Ebola Virus Disease.

Keys: $A$ is question and response on if the participant had heard about EVD and received training; $B$ is question and response on the type of training received; $C$ is question and response on what the definition of EVD is?; $D$ is question and response on EVD being a global concern; $E$ is question and response on the place of the latest outbreak of EVD; $F$ is question on how safe to use the same toilet with Ebola patients and the response; $G$ is question on incubation period of Ebola disease and the response; $\mathrm{H}$ is questions of treatment, availability of immunization, can the disease be transmitted sexually and the participant response; I is questions and response on the signs and symptoms of the EVD. 
worker, and from their children.

The majority of the respondents $(68 \%)$ or 85 out of 125 indicated that is a rare and deadly disease with high mortality rate, as shown in Figure 1C. This is in line with the correct definition of the Ebola virus. This result shows that for every three respondents, two will get the definition of Ebola disease correct. This shows that respondents are generally aware of what the Ebola disease is, when compared to a 1:3 ratio of respondents who got the definition of the Ebola disease incorrect.

The question on if Ebola Virus Disease is global health concern was answered correctly. The results in Figure 1D show that $95 \%(n=124)$ of the responses found the Ebola disease to be a global health concern compared to $5 \%(n=7)$ who indicated that it was not. Figure $1 \mathrm{E}$ showed the response of the participant about the question "where was the latest outbreak of EVD?" The majority (68\%) of the respondents ( $n=89$ of 126) indicated that the latest outbreak of the Ebola virus disease was in West Africa.

The question "is it safe to use the same toilet with Ebola patients?" according to Figure $1 \mathrm{~F}$, the majority of the respondents $73 \%$ (95 of 131) indicated that it is not safe to use the same toilet with patients suffering with the Ebola disease. The answer to the question on incubation period of EVD was shown in Figure 1G. The majority of the respondents indicated that the incubation period of the Ebola disease is between 2 to 21 days. This is indicated by $59 \%$ of respondents or 78 out of 132 as indicated.

Figure $1 \mathrm{H}$ shows that the majority of the respondents 84 out of $131(64 \%)$ indicated that a person can contract Ebola from a person who is infected but does not have high fever or any symptoms present. This was their response to the question on transmission and treatment of Ebola patients. In addition, 36\% (48 of 132) indicated that Ebola can be transmitted sexually while 43 out of 132 or $33 \%$ indicated that there is immunization available for the treatment of Ebola. Of 129 respondents, 60 or $47 \%$ of respondents indicated that there is specific treatment for Ebola. On the question "what are the sign and symptoms of the Ebola disease?" The results show that 126 out of 131 respondents (96\%) indicated that the signs and symptoms of the disease caused by the Ebola virus are high fever $\left(>38.6^{\circ} \mathrm{C}\right)$, severe headaches, muscle pain, vomiting, diarrhea and stomach pain (Figure 11).

Figure 2 showed the response of the participant on their attitude towards Ebola patients and themselves after nursing Ebola patients. Figure 2A showed that feelings of nervousness (36\%) and fear (35\%) were reported by respondents when providing services for a patient who was diagnosed with the Ebola disease. The response of the participants showed in Figure 2B that the lack of relevant skills to treat Ebola in South
A

Providing services for a patient who is diagnosed with the Ebola disease

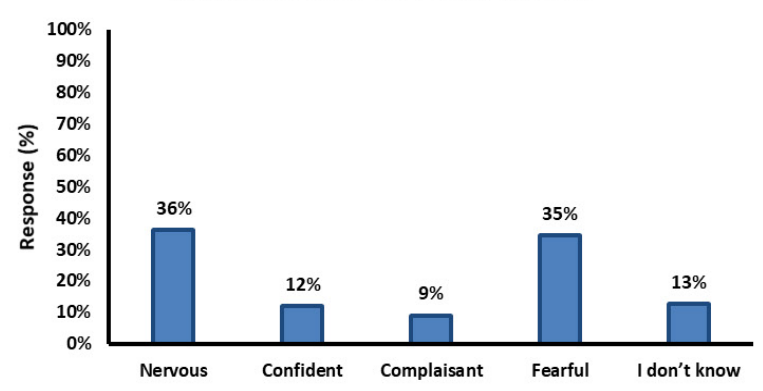

B

Main concern when you think about the Ebola disease

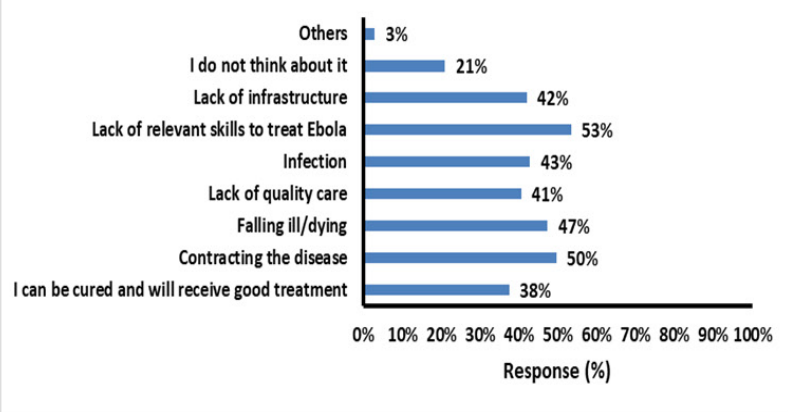

C Worried about yourself, whilst you are nursing these patients, who would you talk to

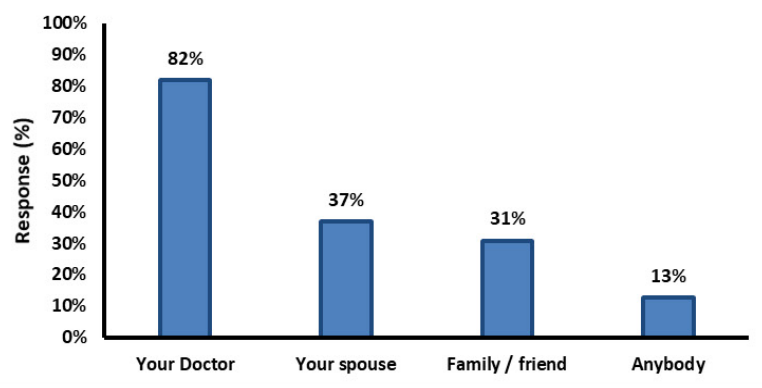

Figure 2: Questions and responses from the participants about their attitude toward EVD patients.

Keys: $A$ is question and response on the participant feeling when providing services for a patient who is diagnosed with the Ebola disease; $\mathrm{B}$ is question and response on their main concern when they think about the Ebola disease; $\mathrm{C}$ is question and response on their worry about themselves while nursing Ebola patients and who they will prefer to talk to. 
Africa was their main concern (35\%). This response (lack of skills to treat the Ebola patients) was followed by their concern about contracting the disease (50\%). The majority of the participants said they will talk to their doctor if they have worries after treating Ebola patients (Figure 2C).

The preparedness of the participants (Health worker) towards EVD is shown in Figure 3. Figure 3A showed the response of the participants to the question "actions that help in transmitting the infection (Ebola disease) to the health care workers". The Figures shows that $96 \%$ or 123 out of 128 respondent's shows that the following are the hand hygiene actions that prevent the transmission of the infection to the Health Care Workers: A) After touching a patient; B) Immediately after a risk of body fluid exposure; and C) After exposure to the immediate surroundings of a patient.

The majority of the respondents indicated that to protect oneself against contracting the Ebola disease (Figure 3B), one need to: 'Wash hands frequently' (92\%); 'Avoiding contact with blood and bodily fluids of any person, particularly who is sick' (89\%); 'Do not handle items that may have come in contact with any infected person's blood and bodily fluid (clothing, bedding)' (83\%); 'Do not touch the body of someone who has died of Ebola' (71\%); 'Avoiding hospitals where Ebola patients are being cared for' had just above $50 \%$ compared to other responses and 'Seek medical care immediately if you develop high fever and any other following symptoms headache, vomiting, diarrhea, unexplained bleeding' (92\%).

Figure 3 C shows the preparedness of private hospital towards Ebola disease and likelihood of the diseases spreading in South Africa. $80 \%$ of the respondents feel that it is likely that the Ebola virus could spread to South Africa compared to $11 \%$ who do not think so. Only $48 \%$ of respondents feel that private hospitals in South Africa are ready to care for patients who are admitted with the Ebola disease, compared to $32 \%$ who do not think so. The response of the participants towards protecting themselves against Ebola infections is shown in Figure 3D. The results show that $84 \%$ of the respondents indicated that 'A. Anyone entering the patient's room should wear gloves, a gown, eye protection (goggles, face shield) and face mask'; 'B. Additional personal protective equipment (PPE)'; and ' $\mathrm{C}$. Should frequently perform hand hygiene before and after patient contact, contact with potential infectious material, and before putting on and after removing PPE, including gloves'.

\section{Discussion}

The knowledge of the respondents in this study showed that they understood the definition of Ebola virus and that the disease is a global health concern. The
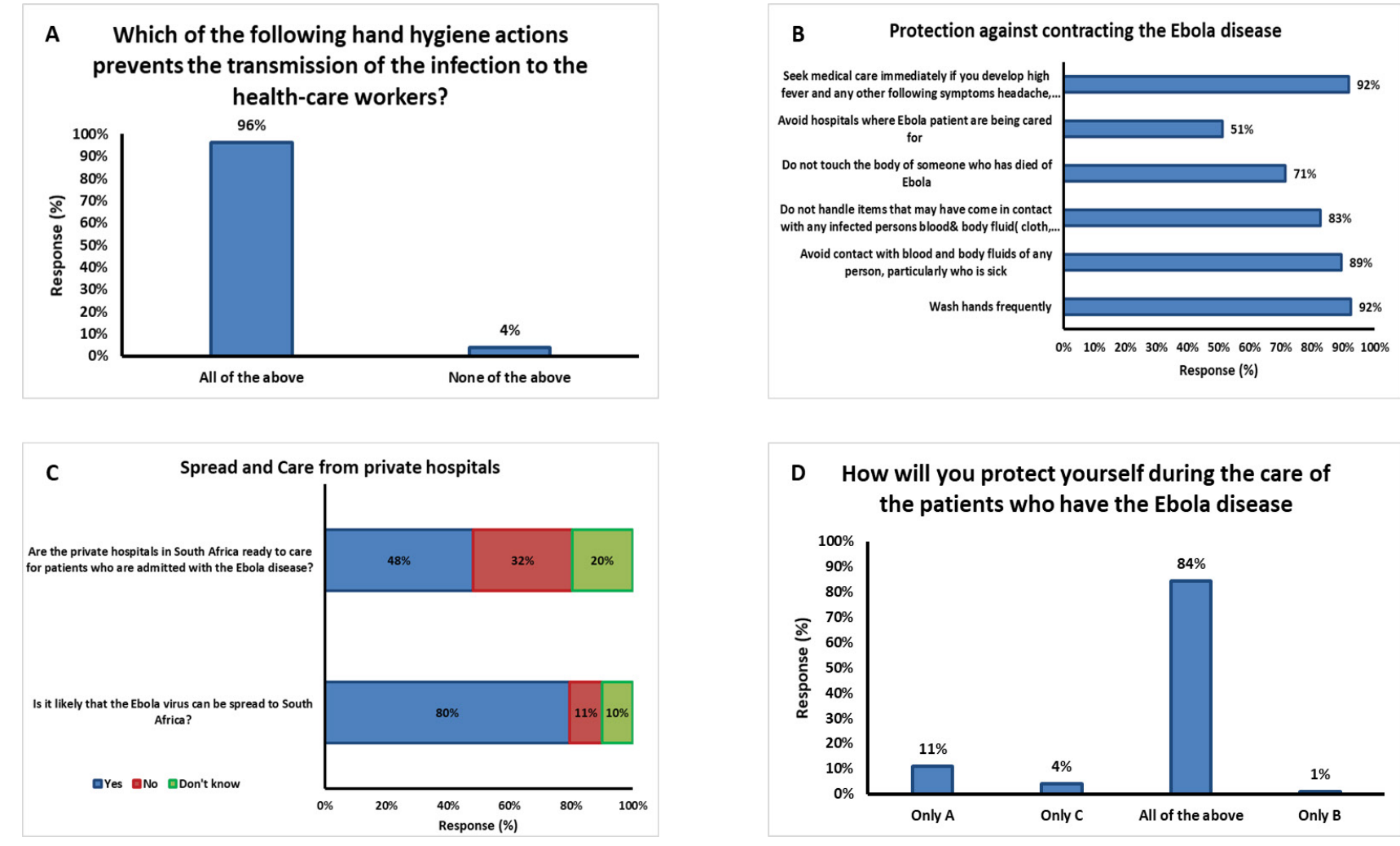

D How will you protect yourself during the care of the patients who have the Ebola disease

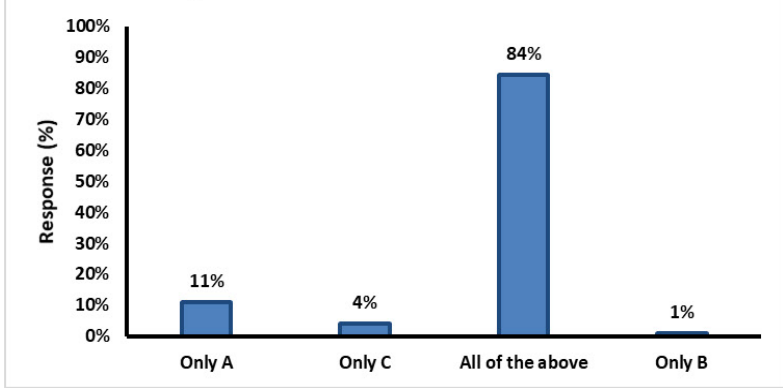

Figure 3: Questions and responses from the participants about their preparedness toward EVD patients.

Keys: $A$ is question and response on actions that help in transmitting of Ebola disease from patients to Health workers; $B$ is question and response on best protection against contracting Ebola disease; $C$ is question and response on preparedness of private hospital towards handling Ebola patients and the likelihood of EVD spreading in South Africa; D is the question and response on how the participant will protect themselves during the care of the patients who have Ebola disease? 
findings in this study are supported by Hisam \& Rana [10] who indicated that most of the respondents in the similar study they conducted had a basic understanding of EVD. Also, Liu, et al. [11] reported that the epidemic situation of Ebola disease may continue and may spread to other countries as well. This shows that the respondents had knowledge regarding EVD being a global health concern when compared to only $7 \%$ who has answered this question incorrectly. Since the knowledge of the respondents were correct about the EVD as a global health concern, it was not surprised that $68 \%$ of them knew that the last outbreak of Ebola virus disease was in West Africa. The study results are supported by [12] who said the Zaire species is responsible for the 2014 West Africa outbreak, which was the last outbreak recorded. Furthermore, the recently reported outbreak was spread to West Africa, which was the largest and the deadliest ever [13].

The answer given by $75 \%$ of the respondents about the mode of transmission of Ebola disease which was through person to person, direct contact with blood and other bodily fluid of someone who is sick was contrary from the findings of Kobayashi, et al. [14]. They reported that across all countries with high or low incidences of Ebola, the respondents were somewhat less able to correctly recognize Ebola transmission. Alfaki, et al. [15] also found that there were significant differences in the knowledge of doctors and allied health care providers regarding the modes of transmission and clinical manifestations.

The response of the respondents on the how the Ebola disease outbreak starts was poor as only 23\% (31 out of 133) have an idea compared to $77 \%$ who did not know. Incubation period of two to 21 days of the Ebola disease was correctly answered by $59 \%$ of respondents, indicating that most of the respondents have knowledge about this period in line with Jarrelts' [5] study that the virus has an incubation period of between two and 21 days from the onset of presenting symptoms. This is in line with Gostin, Lucey, and Phelan [16] who found that in line with EVD's incubation period, quarantine must last up to 21 days. Thus, most of the respondents did not have knowledge of when the outbreak started but had knowledge on the incubation period of EVD [17].

The signs and symptoms of EVD were answered correctly, which showed that the respondents are fully aware of the signs and symptoms of EVD. Most of the respondents indicated that the signs and symptoms of the Ebola disease are high fever $\left(>38.6{ }^{\circ} \mathrm{C}\right)$, severe headache, muscle pain, vomiting, diarrhea, stomach pain, unexplained bleeding which was correctly answered compared to only $4 \%$ who did not know. This results in line with the findings of Kobayashi, et al. [14]. They found that the areas of concern included large numbers of respondents not being confident with Ebola symptom identification. According to Sheikh, et al. [18], their study reported fever as a feature by $120(80 \%)$ doctors, $30(60 \%)$ nurses, bleeding from any site was reported as a feature by 135 (90\%) doctors, 20 (40\%) nurses, and 18 (51\%) laboratory technicians.

The lack of relevant skills to treat Ebola in South Africa contributed to the attitude of the respondents in this study. Seventy-nine percent (79\%) indicated that EVD is likely to spread in a private hospital, however the readiness to care for patients who are admitted with the Ebola disease from the private hospitals in South Africa is a concern to thirty-two percent (32\%) of the respondents. Sixty eight percent $(68 \%)$ of the respondents were confident that South African private hospitals could care for patients who are admitted with the Ebola virus if the health care workers are given adequate training and equipment's. This response was supported by Hisam and Rana [10] who stated that attitude of the health care workers on EVD is lagging in countries where the spread of the disease has not been established. The health care workers used for this study showed the right attitude in given the patients with the virus the outmost care if all the protectives gadgets are provided since they knew how the virus can be transmitted.

The level of preparedness of the health care workers in this study is of a great concern. Feelings of nervousness (36\%) and fear (35\%) were reported by the respondents when providing services for a patient who had been diagnosed with the Ebola disease, while the lack of relevant skills to treat Ebola in South Africa was the main concern to majority of the respondents (53\%), followed by contracting the disease (50\%) [19]. Most of the respondents (82\%) would talk to a doctor. In addition, the possibility of the Ebola virus spreading to South Africa was correctly answered by 105 out of 133 respondents (79\%), while the question on whether private hospitals in South Africa were ready to care for patients who were admitted with the Ebola disease was incorrectly answered by 90 respondents out of 133 respondents (68\%). Kobayashi's [14] study found that $40 \%$ of the respondents saw a risk of Ebola at Hajj, but $45 \%$ of pilgrims had no fear of contracting Ebola during the Hajj. This was contrary to the findings of this study that $35 \%$ of respondents were fearful and $36 \%$ were nervous, which is a sign that South African private hospitals were not ready if most of the respondents were not yet confident in caring for patients affected by this disease. Only $12 \%$ of respondents indicated that they should be confident in caring for these patients, which is contrary to the response they gave for their attitude toward the patient.

As of the time of this study, the world has not experienced the pandemic (COVID-19) which is still ravaging. The knowledge, attitude of the health workers and the care givers are very important in taking care of patients with difference diseases. South Africa health 
care workers still need to be trained and encouraged by the Government in term of policy and renumerations.

\section{Conclusion}

The results of this study show that the fact that the Ebola virus disease (EVD) is a global health issue is widely known in South Africa health care workers. The signs and symptoms of the virus are also understood by the health care workers. The attitude and their preparedness of the health care workers are based on the provision of protective equipment by the management of the hospital and special training.

\section{Acknowledgements}

The authors would like to acknowledge everyone that took part in this study, and the management of Mediclinic Hospital, South Africa for permission to carry out this study.

\section{Conflict of Interest}

The author would like to state that there is no conflict of interest between the authors and there is not external fund for this study.

\section{References}

1. Ansumana R, Keitell S, Roberts GMT, Ntoumi F, Petersen $E$, et al. (2017) Impact of infectious disease epidemics on tuberculosis diagnostic, management, and prevention services: Experiences and lessons from the 2014-2015 Ebola virus disease outbreak in West Africa. Int J Infect Dis 56: 101-104.

2. Frontières MS (2008) Filovirus haemorrhagic fever guideline. Médecins Sans Frontières, Barcelona, Spain, 39-48.

3. Kishore S, Singh R (2014) Ebola virus disease - An update. Indian J Community Health 26: 443-445.

4. WHO (2014) Ebola Response Roadmap - Situation Report Update. World Health Organization.

5. Jarrett A (2015) Ebola: A practice summary for nurse practitioners. The Journal for Nurse Practitioners 11: 16-26.

6. Sarti AJ, Sutherland S, Robillard N, Kim J, Dupuis K, et al. (2015) Ebola preparedness: A rapid needs assessment of critical care in a tertiary hospital. CMAJ Open 3: E198-E207.
7. Amoran OE, Onwube OO (2013) Infection control and practice of standard precautions among healthcare workers in northern Nigeria. J Glob Infect Dis 5: 156-163.

8. Msimang V, Weyer J, le Roux C, Leman P, Kemp A (2013) Dengue fever in South Africa: An imported disease. National Institute for Communicable Diseases Surveillance Bulletin 11: 58-62.

9. Motsoaledi A (2014) Health budget vote speech by the Minister of Health. Government of Republic of South Africa, Pretoria, South Africa.

10. Hisam A, Rana MN, Rahman MU (2016) Knowledge and attitude regarding Ebola virus disease among medical students of Rawalpindi: A preventable threat not yet confronted. Pak J Med Sci 32: 1015-1019.

11. Liu Y, Li T, Liu Y, Hao Y, Wang J, et al. (2015) Development of HIV-1 vaccines based on replication competent Tiantan vaccinia vector in China. The Lancet 386: S10.

12. Feldmann H, Geisbert TW (2011) Ebola haemorrhagic fever. Lancet 377: 849-862.

13. Molinari NAM, LeBlanc TT, Stephens W (2018) The impact of a case of Ebola virus disease on emergency department visits in Metropolitan Dallas-Fort Worth, TX, July, 2013-July, 2015: An interrupted time series analysis. PLoS Curr 10.

14. Kobayashi M, Beer KD, Bjork A, Chatham-Stephens K, Cherry CC, et al. (2015) Community knowledge, attitudes, and practices regarding Ebola virus disease - five counties, Liberia, September-October, 2014. MMWR Morb Mortal Wkly Rep 64: 714-718.

15. Alfaki MM, Salih AMM, Elhuda DA, Egail MS (2016) Knowledge, attitude and practice of health care providers toward Ebola virus disease in hotspots in Khartoum and White Nile states, Sudan, 2014. Am J Infect Control 44: 2023.

16. Gostin LO, Lucey D, Phelan A (2014) The Ebola epidemic: A global health emergency. JAMA 312: 1095-1096.

17. Yakubu A, Folayan MO, Sani-Gwarzo N, Nguku P, Peterson $\mathrm{K}$, et al. (2016) The Ebola outbreak in Western Africa: Ethical obligations for care. J Med Ethics 42: 209-210.

18. Sheikh NS, Sheikh AS, Sheikh AA (2004) Knowledge, attitude and practices regarding Crimean-Congo haemorrhagic fever among healthcare workers in Balochistan. J Ayub Med Coll Abbottabad 16: 39-42.

19. Summers A, Nyenswah TG, Montgomery JM, Neatherlin J, Tappero JW, et al. (2014) Challenges in responding to the ebola epidemic - four rural counties, Liberia, AugustNovember 2014. MMWR Morb Mortal Wkly Rep 63: 12021204. 